\title{
Reliability of temperatures measured at standard monitoring sites as an index of brain temperature during deep hypothermic cardiopulmonary bypass conducted for thoracic aortic reconstruction
}

\author{
Takashi Akata, MD, PhD, ${ }^{\mathrm{a}, \mathrm{b}}$ Hidekazu Setoguchi, MD, PhD, ${ }^{\mathrm{a}}$ Kazuhiro Shirozu, MD, ${ }^{\mathrm{b}}$ and Jun Yoshino, MD
}

Supplemental material is available online.
From the Department of Anesthesiology and Critical Care Medicine, ${ }^{\mathrm{a}}$ Faculty of Medicine, Kyushu University Hospital, and Department of Anesthesiology and Critical Care Medicine, ${ }^{\mathrm{b}}$ Graduate School of Medical Sciences, Kyushu University, Fukuoka, Japan.

Received for publication Aug 14, 2006; revisions received Nov 9, 2006; accepted for publication Nov 17, 2006.

Address for reprints: Takashi Akata, Department of Anesthesiology and Critical Care Medicine, Faculty of Medicine, Kyushu University, Fukuoka 812-8582, Japan. (E-mail: akata@kuaccm.med.kyushu-u.ac.jp).

J Thorac Cardiovasc Surg 2007;133:1559-65 $0022-5223 / \$ 32.00$

Copyright $(9) 2007$ by The American Association for Thoracic Surgery

doi:10.1016/j.jtcvs.2006.11.031
Objective: It is essential to estimate the brain temperature of patients during deliberate deep hypothermia. Using jugular bulb temperature as a standard for brain temperature, we evaluated the accuracy and precision of 5 standard temperature monitoring sites (ie, pulmonary artery, nasopharynx, forehead deep-tissue, urinary bladder, and fingertip skin-surface tissue) during deep hypothermic cardiopulmonary bypass conducted for thoracic aortic reconstruction.

Methods: In 20 adult patients with thoracic aortic aneurysms, the 5 temperature monitoring sites were recorded every 1 minute during deep hypothermic $\left(<20^{\circ} \mathrm{C}\right)$ cardiopulmonary bypass. The accuracy was evaluated by the difference from jugular bulb temperature, and the precision was evaluated by its standard deviation, as well as by the correlation with jugular bulb temperature.

Results: Pulmonary artery temperature and jugular bulb temperature began to change immediately after the start of cooling or rewarming, closely matching each other, and the other temperatures lagged behind these two temperatures. During either situation, the accuracy of pulmonary artery temperature measurement $\left(0.3^{\circ} \mathrm{C}-0.5^{\circ} \mathrm{C}\right)$ was much superior to the other measurements, and its precision (standard deviation of the difference from jugular bulb temperature $=1.5^{\circ} \mathrm{C}-1.8^{\circ} \mathrm{C}$; correlation coefficient $=$ 0.94-0.95) was also best among the measurements, with its rank order being pulmonary artery $\geq$ nasopharynx $>$ forehead $>$ bladder $>$ fingertip. However, the accuracy and precision of pulmonary artery temperature measurement was significantly impaired during and for several minutes after infusion of cold cardioplegic solution.

Conclusions: Pulmonary artery temperature measurement is recommended to estimate brain temperature during deep hypothermic cardiopulmonary bypass, even if it is conducted with the sternum opened; however, caution needs to be exercised in interpreting its measurements during periods of the cardioplegic solution infusion.

$\mathrm{D}$ eep hypothermia $\left(<20^{\circ} \mathrm{C}\right)$ has been used as a means of protection against tissue ischemia during circulatory arrest deliberately induced to facilitate repair of congenital heart disease, aortic arch reconstruction, and neurosurgical procedures. Thus, during induction of deep hypothermia and subsequent circulatory arrest, it is essential to estimate brain temperature to ensure that the brain - the most vital organ vulnerable to decreased $\mathrm{O}_{2}$ delivery-actually receives the benefit of the desired degree of hypothermia and is not on the verge of hazardous hypothermia.

Stone and colleagues ${ }^{1}$ previously measured brain temperature using a thermocouple embedded in the cerebral cortex in patients who underwent deep hypothermic cardiopulmonary bypass (CPB) for repair of cerebral aneurysms. They compared the brain temperature with temperatures measured at 8 standard monitoring 


\section{Abbreviations and Acronyms \\ $\mathrm{CPB}=$ cardiopulmonary bypass \\ FHDTT $=$ forehead deep-tissue temperature \\ FSST = fingertip skin-surface temperature \\ JBT = jugular bulb temperature \\ NPT = nasopharyngeal temperature \\ PA $=$ pulmonary artery \\ PAT = pulmonary artery temperature \\ UBT = urinary bladder temperature}

sites (ie, nasopharynx, esophagus, pulmonary artery [PA], tympanic membrane, urinary bladder, rectum, axilla, foot) during cooling, stabilization, and rewarming. They found that, among those sites, measurements from the nasopharynx, esophagus, and PA tend to match the brain temperature best, although at times they either overestimate or underestimate the brain temperature. In a previous study with pigs, Stefaniszyn and associates ${ }^{2}$ measured brain temperature with a needle temperature probe inserted into the superficial parietal cortex with the skull minimally opened, reporting that neither nasopharyngeal nor rectal temperature closely reflected the brain temperature during deep hypothermic CPB conducted with the sternum opened. Thus, any of the standard monitoring sites may not accurately reflect changes in brain temperature during deep hypothermic CPB.

Because $99 \%$ of the jugular bulb blood is derived from intracerebral vasculature, the jugular bulb temperature (JBT) has been considered as an accurate index of cerebral cortical temperature. ${ }^{3-6}$ Indeed, JBT closely reflected changes in cerebral parenchymal temperature measured with the skull minimally opened during deliberate hypothermia in a wellcontrolled study in canines. ${ }^{7}$ Some investigators have compared changes in the JBT with those in nasopharyngeal, tympanic, or rectal temperature during deep hypothermic CPB conducted for cardiac surgeries, suggesting that none of those standard monitoring sites accurately reflects changes in brain temperature. ${ }^{4,5}$ In this study, we compared changes in JBT with those in pulmonary artery temperature (PAT), nasopharyngeal temperature (NPT), forehead deep-tissue temperature (FHDTT), urinary bladder temperature (UBT), and fingertip skin-surface temperature (FSST) during deep hypothermic $\mathrm{CPB}$ in adult patients with thoracic aortic aneurysms. We demonstrate for the first time that despite the intrathoracic procedure and the lack of physiologic PA blood flow, PAT closely reflects changes in JBT and thus presumably those in brain temperature during deep hypothermic CPB except during periods of the cardioplegic solution infusion.

\section{Materials and Methods}

This prospective observational study was performed in 20 consecutive adult patients ( 9 women, 11 men; age $70 \pm 9$ years; height, $160 \pm 10 \mathrm{~cm}$; weight, $58 \pm 10 \mathrm{~kg}$ ) with thoracic aortic aneurysms
(12 dissecting, 8 saccular) who underwent deep hypothermic $\left(<20^{\circ} \mathrm{C}\right) \mathrm{CPB}$ and circulatory arrest for reconstruction of the thoracic aorta (4 ascending, 16 arch). The conduct and monitoring of deep hypothermic CPB, as well as general anesthetic management for this type of surgery, are standardized in our institute, except doses of anesthetic and cardiovascular agents, which are clinically determined in each patient. Because any intervention was not made in this study, approval and informed consent on this study was not required from our institute and patients, respectively.

\section{Anesthetic Management and Intraoperative Monitoring}

Anesthesia was induced with midazolam, fentanyl, and sevoflurane and subsequently maintained with midazolam, fentanyl, propofol, and sevoflurane in oxygen. The lungs were ventilated mechanically to maintain $\mathrm{PaCO}_{2}$ at $\sim 35 \mathrm{~mm} \mathrm{Hg}$. Besides the basic anesthetic safety monitors, radial artery, femoral artery, and PA catheters and transesophageal echocardiography were used to monitor cardiovascular functions. In addition, an oximetry catheter (OW173H-4F, 4 F/40 cm, Edwards Lifesciences LLC, Irvine, Calif) was placed in the right jugular venous bulb to monitor oxygen saturation and temperature of the jugular venous blood; its appropriate placement was confirmed by brain radiograph in each patient. The PA catheter (746HF8, Swan-Ganz CCOmbo CCO/ $\mathrm{SvO} 2 / \mathrm{VIP}, 8 \mathrm{~F} / 110 \mathrm{~cm}$, Edwards Lifesciences LLC) was placed at the most proximal point where the PA occlusion pressure waveform could be obtained with the balloon inflated with $1.5 \mathrm{~mL}$ of air, and its placement was evaluated by chest radiograph and transesophageal echocardiography. In all patients, the PA catheter was found to be placed in the right PA immediately behind the superior vena cava.

The JBTs and PATs were monitored with a thermistor placed at the tip of the jugular bulb and PA catheters, respectively. NPT was monitored by placing a thermistor probe in the posterior nasopharynx ( $\sim 5 \mathrm{~cm}$ from the external naris). FHDTT was monitored by placing a $4.5-\mathrm{cm}$-diameter sensor probe designed for measurement of the deep-tissue temperature (PD-11, Terumo, Tokyo, Japan) on the forehead. UBT was monitored using a thermistor-tipped urinary bladder catheter (Respiratory Support Products, Inc, Irvine, Calif). FSST was monitored by placing a thermistor probe on the fingertip opposite to the nail bed. All temperature sensors were interfaced with electronic thermometers (AA-900P thermometer, Nihon Kohden, Tokyo, Japan), and the data were electronically sampled and stored at 1-minute interval. The room temperature was maintained at $20^{\circ} \mathrm{C}$.

\section{Conduct of Cardiopulmonary Bypass}

Patients were anticoagulated with heparin $(300 \mathrm{U} / \mathrm{kg})$, and subsequent doses were titrated to keep the activated clotting time above 450 seconds. Cannulas $(28 \mathrm{~F}$ and $32 \mathrm{~F})$ were passed into the superior vena cava and inferior vena cava, respectively, via the right atrium. Roller pumps with a membrane oxygenator were used to achieve a $2.5 \mathrm{~L} \cdot \min ^{-1} \cdot \mathrm{m}^{-2}$ extracorporeal flow via an 8 - or $10-\mathrm{mm}$ vascular graft sutured to the femoral and subclavian arteries, respectively. The bypass circuit was primed using acetated Ringer solution with or without adding packed red blood cells to maintain hematocrit at $20 \%$ to $25 \%$. 
Deep hypothermia (JBT $\left.<20^{\circ} \mathrm{C}\right)$ was rapidly ( $\sim 20$ minutes) induced with a separate water bath heat exchanger, which was initially set at $10^{\circ} \mathrm{C}$. After JBT became lower than $20^{\circ} \mathrm{C}$, the temperature of the water bath was allowed to rise to $15^{\circ} \mathrm{C}$ to $20^{\circ} \mathrm{C}$, where it was maintained until rewarming began. In addition, the patients' heads were cooled with ice packs during induction and maintenance of the hypothermia (without interfering with the FHDTT measurement). After induction of the hypothermia, the aorta was crossclamped, and cold $\left(\sim 4^{\circ} \mathrm{C}\right)$ crystalloid cardioplegic solution was infused into the aortic root or directly into the coronary ostia; its effectiveness was confirmed by appropriate increases in aortic root pressure (in case of aortic root administration) and/or cardioplegic line pressure and immediate cardiac arrest. During aortic arch reconstruction, the circulation was arrested except for the cerebral circulation, into which the hypothermic $\left(20^{\circ} \mathrm{C}\right) \mathrm{CPB}$ perfusate was infused retrograde at a rate of 150 to $200 \mathrm{~mL} / \mathrm{min}$ via the $28 \mathrm{~F}$ cannula placed in the superior vena cava. The CPB was resumed after the aortic arch was reconstructed, and the hypothermia was gradually reversed on CPB. During the rewarming period, the heat exchanger was initially set at $39^{\circ} \mathrm{C}\left(\mathrm{CPB}\right.$ arterial line temperature $\left.<37.5^{\circ} \mathrm{C}\right)$ and later adjusted downward. To attenuate the post-CPB afterdrop (ie, decreases in core temperature after weaning from $\mathrm{CPB}),{ }^{8}$ the $\mathrm{CPB}$ was terminated after UBT reached to $36^{\circ} \mathrm{C}$.

\section{Data Analyses and Statistics}

Using JBT as a standard for brain temperature, we quantified the accuracy and precision of temperature measurements at the 5 standard monitoring sites during the first 40 and 60 minutes of the cooling and rewarming, respectively. Specifically, the accuracy and precision were quantitated as the difference between JBT and each temperature and its standard deviation, respectively (ie, Bland and Altman analyses). The precision was also quantitated with the Pearson's correlation coefficients (ie, correlation between JBT and each temperature). Because it is not possible to measure temperature below $15^{\circ} \mathrm{C}$ with a thermistor of the oximetry catheters used in this study, the data were not analyzed during periods when either JBT or PAT was unmeasurable.

Because the cardioplegic solution infusion seemed to affect the PAT, we evaluated its effects on the difference or correlation between JBT and PAT. In addition, because the data on UBT were variable, we also evaluated the relation between urine volume and changes in UBT, using simple (either linear or non-linear) regression analyses.

The temperature-time relation during either cooling or rewarming was analyzed using analysis of variance and Scheffé $F$ test. Comparisons of the correlation coefficients were made using the Fisher Z-transformation. Any other comparisons between 2 groups were made by either Student $t$ test or Welch $t$ test, depending on the homogeneity of variance. Values were expressed as mean \pm $\mathrm{SD}$, mean $\pm 2 \mathrm{SD}$ (in the Bland and Altman analyses), or mean \pm SEM (for clarity in the temperature-time relation).

\section{Results}

\section{Changes in Body Temperatures During Cooling}

Temperatures measured at the standard core temperature monitoring sites (ie, PAT, NPT, FHDTT, and UBT) closely matched $(P>.05)$ JBT, although FSST was lower $(P<$
.05) than JBT, until the cooling was started (Figure 1). JBT and PAT began to decrease immediately after the start of cooling, closely matching, and the other 4 temperatures lagged $(P<.05)$ behind JBT and PAT (Figure 1$)$.

In the individual analyses, among the 5 standard monitoring sites, PAT best correlated with JBT in 18 patients, and FSST worst in 13 patients. The correlation between JBT and PAT was excellent in all the patients, with its coefficient ranging from 0.946 to 0.996 , although that between JBT and any of the other 4 temperatures was rather variable among the patients, with its coefficient ranging from 0.663 to 0.993. The difference from JBT was the smallest for PAT in 18 patients and the largest for UBT in 14 patients; its SD value was the smallest for PAT in 17 patients and the largest for FSST in 14 patients, and for UBT in 5 patients.

In 9 patients, during the first 40 minutes of the cooling, the cardioplegic solution was infused into coronary circulation for a few $(2.1 \pm 0.3)$ minutes immediately after aortic crossclamping. In all those patients, PAT began to decrease within 1 minute after the cardioplegic solution infusion, resulting in significant deviation from the course of decrease in JBT for several minutes ( $<10$ minutes; Figure 2A). If the data obtained for 10 minutes of the cardioplegic solution infusion were removed from the analyses, the correlation between JBT and PAT was improved in all the patients (Figure 2B). As a result, among the 5 temperatures, PAT best correlated with JBT in all the 20 patients, with the correlation coefficient ranging from 0.977 to 0.999 (Figure 2B). In addition, the difference between JBT and PAT and its SD value also became smaller in 8 of the 9 patients (Figure 2B).

In the overall analyses, PAT also excellently correlated with JBT much closer $(P<.05)$ than the other 4 temperatures, with the rank order of correlation coefficients being $\mathrm{PAT}>\mathrm{NPT}>\mathrm{FHDTT}>\mathrm{UBT}>\mathrm{FSST}$ (Figure 3 ). In the Bland-Altman analyses, the difference from JBT was also much smaller $(P<.05)$ for PAT than for the other 4 temperatures, with its rank order being $\mathrm{PAT}>\mathrm{NPT}=$ FSST $>$ FHDTT $>$ UBT (Figure 3). In addition, its SD value was smaller for PAT than for the other 4 temperatures, with its rank order being $\mathrm{PAT}>\mathrm{NPT}>$ FHDTT $>\mathrm{UBT}>$ FSST (Figure 3).

Also in the overall analyses, removal of the data obtained for 10 minutes of the cardioplegic solution infusion improved the correlation coefficient between JBT and PAT from $0.952(\mathrm{n}=737)$ to $0.964(\mathrm{n}=645 ; P=.008)$. In addition, it decreased the difference between JBT and PAT $(=$ PAT - JBT) from $-0.3 \pm 1.5$ to $-0.07 \pm 1.4$ $(P=.003)$.

\section{Changes in Body Temperatures During Rewarming} Temperatures at the 5 standard monitoring sites all had closely matched JBT with gradients less than $0.7^{\circ} \mathrm{C}$ until the 


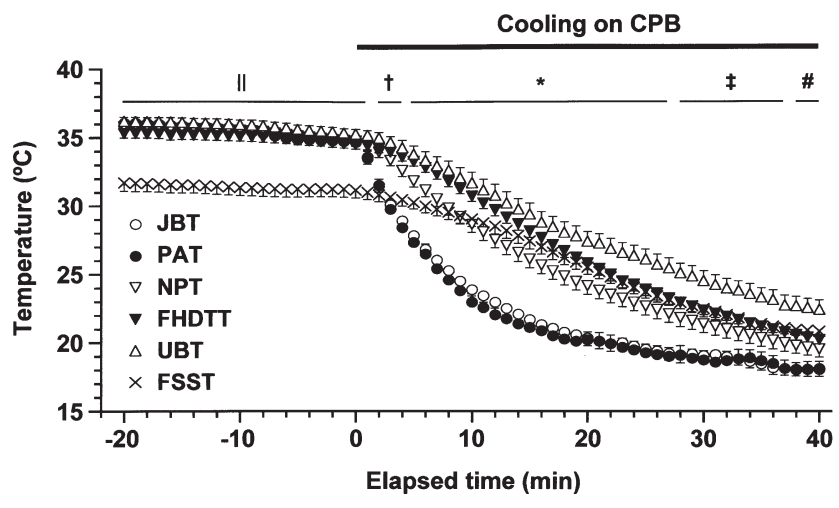

Figure 1. Changes in body temperatures during cooling on total CPB (mean \pm SEM, $n=20$ ). JBT, Jugular bulb temperature; PAT, pulmonary artery temperature; $N P T$, nasopharyngeal temperature; $F H D T T$, forehead deep-tissue temperature; UBT, urinary bladder temperature; FSST, fingertip skin-surface temperature. The differences among 5 groups at each time point are indicated by the following symbols: ${ }^{*} \boldsymbol{P}<.05:$ JBT vs NPT, FHDTT, UBT, and FSST; $\dagger P<.05:$ JBT vs NPT, FHDTT, and UBT; $¥ P<.05:$ JBT vs FHDTT, UBT, and FSST; \#P < .05: JBT vs UBT and FSST; $\| P<.05:$ JBT vs FSST.

rewarming was started. However, during the stabilized hypothermia, the cardioplegic solution infusion also caused transient decreases in PAT to the unmeasurable level (ie, $<15^{\circ} \mathrm{C}$ ), leading to significant differences between PAT and JBT (not shown).

JBT and PAT began to increase immediately after the start of rewarming, closely matching, and the other four temperatures lagged $(P<.05)$ behind JBT and PAT (Figure E1). However, NPT and FHDTT followed JBT and PAT much closer than either FSST or UBT (Figure E1). The accuracy and precision of temperature measurements at the 5 standard monitoring sites as an estimate of JBT observed during the rewarming were substantially identical to those observed during the cooling; thus, the results are not shown as figures in the following sections.

In the individual analyses, among the 5 monitoring sites, PAT and NPT best correlated with JBT in 12 and 7 patients, respectively, and UBT and FSST correlated the least in 15 and 4 patients, respectively. The correlation between JBT and PAT and the correlation between JBT and NPT were both excellent in all the patients, with its coefficient ranging from 0.949 to 0.999 , although that between JBT and any of the other 3 temperatures was variable among the patients, with its coefficient ranging from 0.717 to 0.997 . The difference from JBT was the smallest for PAT in 15 patients and the largest for UBT in 12 patients; its SD value was the smallest for PAT and NPT in 13 and 5 patients, respectively, and the largest for UBT and FSST in 9 and 10 patients, respectively.
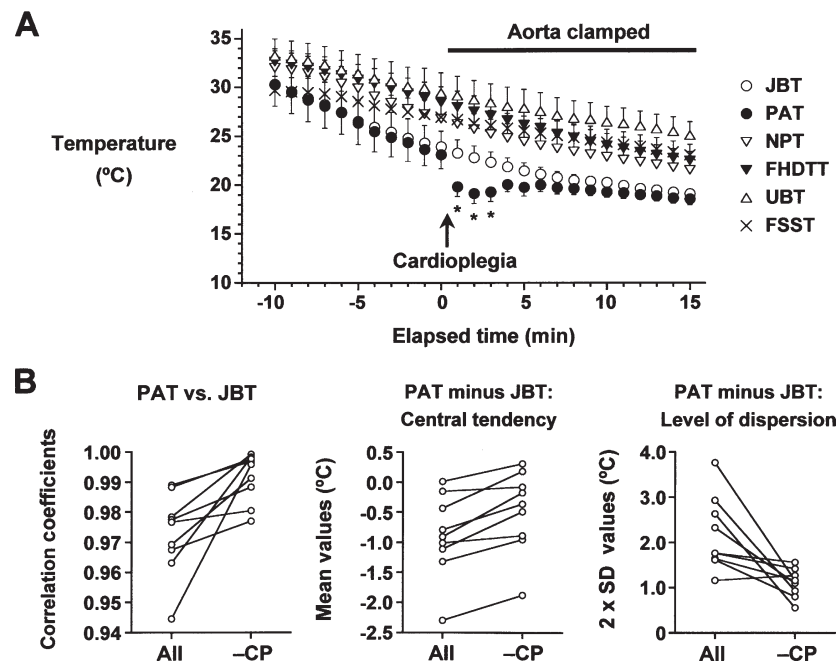

Figure 2. A, Effects of the cardioplegic solution infusion on changes in body temperatures during the cooling (mean \pm SEM, $\mathrm{n}=9$ ). JBT, Jugular bulb temperature; PAT, pulmonary artery temperature; NPT, nasopharyngeal temperature; FHDTT, forehead deep-tissue temperature; UBT, urinary bladder temperature; FSST, fingertip skin-surface temperature. ${ }^{*} P<0.05$ : PAT vs JBT. B, Effects of removal of the data obtained during 10 minutes of the cardioplegic solution infusion from the analyses on the correlation coefficient between PAT and JBT (left), the difference between PAT and JBT (middle), and its standard deviation (right) in the 9 patients. All, Analyses of all the data obtained during 40 minutes of the cooling; $-C P$, analyses of the data obtained during $\mathbf{4 0}$ minutes of the cooling from which the data obtained during $\mathbf{1 0}$ minutes of the cardioplegic injection were removed. ${ }^{*} \boldsymbol{P}<.05$ vs the All group.

In the overall analyses $(\mathrm{n}=1183)$, PAT, NPT, and FHDTT excellently correlated with JBT much closer $(P<$ .05) than UBT or FSST, with the rank order of correlation coefficients being PAT $(0.94)=$ NPT $(0.94)>$ FHDTT $(0.93)>\operatorname{UBT}(0.77)>\operatorname{FSST}(0.65)$. In the Bland-Altman analyses, the difference from JBT was much smaller $(P<$ .05) for PAT than for the other 4 temperatures, with its rank order being PAT $\left(-0.5^{\circ} \mathrm{C}\right)>\mathrm{NPT}\left(-2.1^{\circ} \mathrm{C}\right)>$ FHDTT $\left(-3.5^{\circ} \mathrm{C}\right)>\operatorname{FSST}\left(-6.2^{\circ} \mathrm{C}\right)>\operatorname{UBT}\left(-5.4^{\circ} \mathrm{C}\right)$. However, its $\mathrm{SD}$ value was identical $\left(1.8^{\circ} \mathrm{C}\right)$ among PAT, NPT, and FHDTT and comparable between UBT $\left(3.2^{\circ} \mathrm{C}\right)$ and FHDTT $\left(3.8^{\circ} \mathrm{C}\right)$; as a result, the rank order of level of dispersion was $\mathrm{PAT}=\mathrm{NPT}=$ FHDTT $>$ UBT $>$ FSST .

Relation Between Changes in Bladder Temperature and Urine Volume

Linear regression analyses revealed that the urine volume $(X)$ did not correlate with the change in UBT $(Y)$ during the first 20 minutes of cooling $(Y=6.8+0.01 X ; r=.42 ; P=$ .06) but correlates with the change in UBT during the first 
A

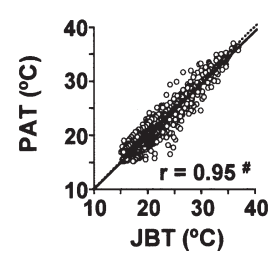

B

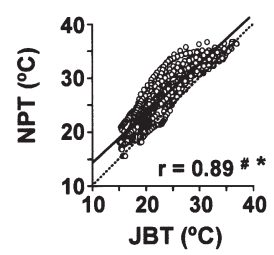

C

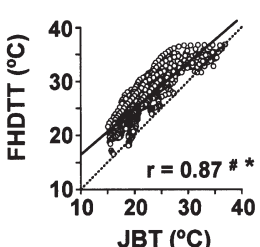

D

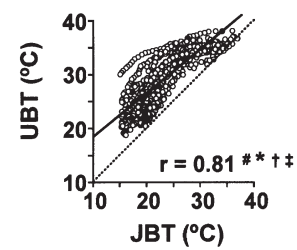

E

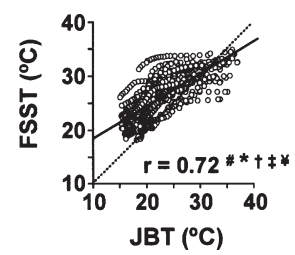

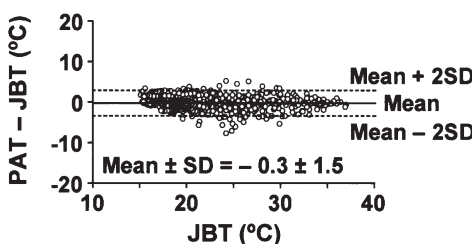
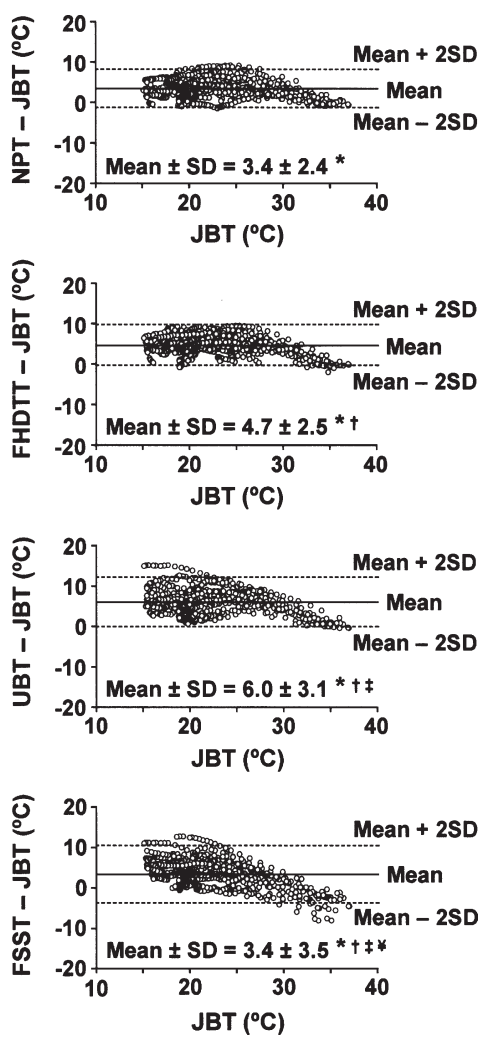

Figure 3. Correlation (left) and the Bland and Altman comparison (right) between jugular bulb temperature (JBT) with either pulmonary artery (A), nasopharyngeal (B), forehead deep-tissue (C), urinary bladder (D), and fingertip skin-surface (E) temperatures during the first $\mathbf{4 0}$ minutes of cooling on total CPB. The data are from all of the 20 patients $(n=737)$. PAT, Pulmonary artery temperature; NPT, nasopharyngeal temperature; FHDTT, forehead deep-tissue temperature; UBT, urinary bladder temperature; $F S S T$, fingertip skin-surface temperature. \#Significant correlation $(P<$ $.0001),{ }^{*} P<.05$ vs PAT, $+P<.05$ vs NPT, $¥ P<.05$ vs FHDTT, $¥ P<$ .05 vs UBT.

30 minutes of rewarming $(Y=1.5+0.01 X ; r=.64 ; P=$ $.002)$. However, simple regression analyses using power, exponential, logarithmic, reciprocal models further revealed that the urine volume $(X)$, transformed to a logarithmic scale, correlates with the change in UBT $(Y)$ both during the first 20 minutes of cooling $(Y=0.1+3.6 \log X ; r=.57$; $P=.009)$ and during the first 30 minutes of rewarming $(Y=-2.5+2.8 \log X ; r=.48 ; P=.03)$.

\section{Discussion}

Pulmonary Artery Temperature

The results indicate that among the 5 standard temperature monitoring sites evaluated in the present study, the PAT measurement best reflects changes in JBT, the best in vivo indicator of brain temperature, ${ }^{6,7}$ during rapid induction of deep hypothermia and its gradual reversal on CPB. The observed degree of accuracy and precision of PAT measurement as an estimate of JBT suggests that PAT reliably reflects changes in brain temperature during deep hypothermic CPB. However, its deviation from JBT associated with the cardioplegic solution infusion indicates that PAT does not serve as a reliable index of brain temperature during and for several minutes after the cardioplegic solution infusion.

The reasons why PAT closely matched JBT during total CPB conducted with the sternum opened would be as follows. Because the brain is a vessel-rich organ, receiving a high proportion $(\sim 15 \%)$ of the cardiac output relative to its weight, brain temperature and thus JBT would change quickly, reflecting changes in the core blood temperature during active cooling or rewarming on CPB. Thus, PAT might have directly reflected the temperature of venous blood of the bronchial circulation returning to the pulmonary vein and subsequently flowing into the PA in a retrograde manner, which would represent the core blood temperature. In addition, because the PA catheter tip was placed in the right PA immediately behind the superior vena cava and ascending aorta, its thermister might have been freed from thermal interference caused by the cool surroundings and intrathoracic procedures; in other words, the thermistor for PAT measurement might have been thermally jacketed by blood flowing at high rate in those great vessels.

Cardioplegic solution-infused antegrade into the coronary circulation would exit the coronary system by way of the coronary sinus, subsequently proceeding into the right ventricle, and eventually into the PA. Thus, during periods of the cardioplegic solution infusion, PAT probably reflected temperature of the cardioplegic solution ejected into the PA, transiently deviating from JBT. Indeed, after the decrease in PAT, we have observed changes in the color of perfusate drained from the left-ventricular vent, indicating its inclusion of the cardioplegic solution. Caution needs to be exercised in interpreting changes in PAT after the cardioplegic solution injection. However, the immediate decrease in PAT after the antegrade infusion of cold cardioplegic solution would suggest its effectiveness.

\section{Nasopharyngeal Temperature}

NPT has long been used as an index of core or brain temperature during moderate hypothermic $\mathrm{CPB}$ in the clinical setting. ${ }^{8-10}$ However, in previous studies measuring brain temperature using a thermometer placed in cerebral cortex, ${ }^{1,2}$ NPT did not closely match brain temperature 
during induction of deep hypothermia (brain temperature $\sim 16^{\circ} \mathrm{C}$ ) and its reversal on CPB, but closely (with gradients $<1.0^{\circ} \mathrm{C}$ ) matched brain temperature during stabilized deep hypothermia. ${ }^{1}$ These findings are not inconsistent with our findings. The degree of accuracy and precision of NPT measurement as an index of JBT observed in this study indicates that NPT does not serve as an accurate index of brain temperature during induction of deep hypothermia and its reversal on CPB. However, the degree of its precision would be high enough to be of benefit in estimating brain temperature during the reversal of hypothermia. The superiority of the degree of precision of NPT measurement during rewarming over that during cooling would be due to the more gradual changes in JBT during rewarming compared with during cooling.

\section{Forehead Deep-tissue Temperature}

Utilizing the deep-tissue thermometry, ${ }^{11,12}$ brain temperature could be noninvasively measured (ie, exteriorized) with an electrically insulated thermistor probe placed on the forehead skin-surface that creates an area of 0 thermal flux between the skin-surface and deep tissue (ie, cerebral tissue). However, as inferred from its principle (ie, time required for the equilibrium), this thermometry (ie, FHDTT measurement) was not useful in estimating rapid changes in core temperature (as estimated by NPT) during induction of moderate hypothermia ${ }^{13,14}$ and its reversal ${ }^{13}$ on CPB. Using JBT as a standard for brain temperature, this study, for the first time, evaluated its usefulness in estimating brain temperature during deep hypothermic CPB. The observed accuracy and precision of FHDTT measurement indicate that FHDTT does not serve as a reliable index of brain temperature during induction of deep hypothermia and its reversal on CPB but closely matches brain temperature during stabilized deep hypothermia. The observed discrepancy between NPT and FHDTT during deep hypothermic CPB is consistent with the previous observation during moderate hypothermic $\mathrm{CPB} .{ }^{13}$

\section{Urinary Bladder Temperature}

Urine is a filtrate of plasma through the kidneys, which receive $20 \%$ to $25 \%$ of the cardiac output. Thus, if the urine flow rate were high, UBT would closely match the core blood temperature. However, even with the high urine flow rate, UBT, which represents the average temperature of urine stored in the bladder, would fail to follow rapid changes in the core blood temperature. Thus, during a period of hypothermic CPB when the urine flow rate normally decreases and the core blood temperature rapidly changes, UBT would not serve as an accurate index of the core blood or brain temperature. Indeed, in previous studies, ${ }^{1,3,15-17}$ UBT lagged substantially behind brain temperature, JBT, or other core temperature monitoring sites (eg, PAT, NPT, esophageal temperature) during induction of hypothermia and its reversal on CPB. In addition, during rewarming on $\mathrm{CPB}$, the difference between UBT and NPT increased with lower urine flow rates. ${ }^{15}$ This study confirmed the unreliability of UBT measurement as an index of the core blood or brain temperature during cooling or rewarming on $\mathrm{CPB}$, as well as its dependence on urine flow rate. However, UBT closely matched JBT and other core temperature monitoring sites both during stabilized normothermia (before the start of cooling) and during stabilized hypothermia (before the start of rewarming).

\section{Fingertip Skin-surface Temperature}

The observed degree of accuracy and precision of FSST measurement as an index of JBT indicates that FSST is not a reliable index of brain temperature during cooling or rewarming on CPB. This is consistent with the previous findings that peripheral skin-surface temperature variably deviated from core temperature during the intraoperative period (even without CPB) ${ }^{18-20}$ However, in this study, FSST closely matched JBT during stabilized deep hypothermia. In addition, the peripheral skin-surface temperature has previously been suggested to serve as an indicator of the adequate rewarming at the end of $\mathrm{CPB}$ or a predictor of the post-CPB afterdrop. ${ }^{9,10}$ Furthermore, in our previous study, ${ }^{21}$ FSST closely correlated with fingertip blood flow, suggesting its usefulness in the assessment of peripheral circulation (which would be important after weaning from the $\mathrm{CPB}$ ).

\section{Other Temperature Monitoring Sites}

Distal esophageal temperature has been proposed to serve as a reliable index of brain or core blood temperature during hypothermic CPB. ${ }^{22-25}$ However, nowadays, the standard use of transesophageal echocardiography does not allow us to measure the esophageal temperature in most adult patients undergoing cardiovascular surgeries.

The tympanic membrane is situated at the immediate vicinity of internal carotid artery and supplied by its branches. Thus, its temperature had been considered to closely reflect cerebral — and thus hypothalamic - temperature in earlier thermoregulatory studies. ${ }^{26,27}$ However, it has been shown that the tympanic temperature is lower than hypothalamic temperature, ${ }^{28-30}$ and that those 2 temperatures even can shift in opposite directions. ${ }^{28,29}$ In addition, the tympanic temperature has been shown to be altered by changes in face or head skin temperature. ${ }^{31-33}$ Furthermore, perforation of the tympanic membrane was previously reported as a complication of the tympanic thermometry during anesthesia. ${ }^{34}$ Thus, the tympanic thermometry is not used in our operating rooms.

Rectal temperature has been shown to lag significantly behind rapid changes in core temperature (eg, PAT, NPT) during hypothermic $\mathrm{CPB} .{ }^{1,22-24}$ 


\section{Conclusions}

During deep hypothermic, total CPB conducted for repair of thoracic aortic aneurysms, a right PA catheter thermistor would reliably reflect changes in brain temperature. However, caution needs to be exercised in interpreting its measurements during and for several minutes after the cardioplegic solution infusion.

\section{References}

1. Stone JG, Young WL, Smith CR, Solomon RA, Wald A, Ostapkovich $\mathrm{N}$, et al. Do standard monitoring sites reflect true brain temperature when profound hypothermia is readily induced and reversed? Anesthesiology. 1995;82:344-51.

2. Stefaniszyn HJ, Novick RJ, Keith FM, Salerno TA. Is the brain adequately cooled during deep hypothermic cardiopulmonary bypass? Curr Surg. 1983;40:294-7.

3. Crowder CM, Tempelhoff R, Theard A, Chen MA, Todorov A, Dacey RG Jr. Jugular bulb temperature: comparison with brain surface and core temperatures in neurosurgical patients during mild hypothermia. J Neurosurg. 1996;85:98-103.

4. Sandstrom K, Nilsson K, Andreasson S, Larsson LE. Jugular bulb temperature compared with non-invasive temperatures and cerebral arteriovenous oxygen saturation differences during open heart surgery. Paediatr Anaesth. 1999;9:123-8.

5. Kaukuntla H, Harrington D, Bilkoo I, Clutton-Brock T, Jones T, Bonser RS. Temperature monitoring during cardiopulmonary bypass-do we undercool or overheat the brain? Eur J Cardiothorac Surg. 2004;26:580-5.

6. Nussmeier NA. Management of temperature during and after cardiac surgery. Tex Heart Inst J. 2005;32:472-6.

7. Ao H, Moon JK, Tanimoto H, Sakanashi Y, Terasaki H. Jugular vein temperature reflects brain temperature during hypothermia. Resuscitation. 2000;45:111-8.

8. Ramsay JG, Ralley FE, Whalley DG, DelliColli P, Wynands JE. Site of temperature monitoring and prediction of afterdrop after open heart surgery. Can J Anaesth. 1985;32:607-12.

9. Muravchick S, Conrad DP, Vargas A. Peripheral temperature monitoring during cardiopulmonary bypass operation. Ann Thorac Surg. 1980;29:36-41.

10. Rajek A, Lenhardt R, Sessler DI, Brunner G, Haisjackl M, Kastner J, et al. Efficacy of two methods for reducing postbypass afterdrop. Anesthesiology. 2000;92:447-56.

11. Fox RH, Solman AJ. A new technique for monitoring the deep body temperature in man from the intact skin surface. J Physiol (Lond). 1971;212:8-10.

12. Fox RH, Solmon AJ, Isaacs R, Fry AJ. A new method for monitoring deep body temperature from the skin surface. Clin Sci. 1973;44:81-6.

13. Muravchick S. Deep body thermometry during general anesthesia. Anesthesiology. 1983;58:271-5.

14. Sakuragi T, Mukai M, Dan K. Deep body temperature during the warming phase of cardiopulmonary bypass. Br J Anaesth. 1993;71: 583-5.

15. Horrow JC, Rosenberg H. Does urinary catheter temperature reflect core temperature during cardiac surgery? Anesthesiology. 1988;69: 986-9.
16. Bone ME, Feneck RO. Bladder temperature as an estimate of body temperature during cardiopulmonary bypass. Anaesthesia. 1988;43: 181-5.

17. Akata T, Yamaura K, Kandabashi T, Sadamatsu S, Takahashi S. Changes in body temperature during profound hypothermic cardiopulmonary bypass in adult patients undergoing aortic arch reconstruction. J Anesth. 2004;18:73-81.

18. Cork RC, Vaughan RW, Humphrey LS. Precision and accuracy of intraoperative temperature monitoring. Anesth Analg. 1983;62:211-4.

19. Sessler DI, Olofsson CI, Rubinstein EH, Beebe JJ. The thermoregulatory threshold in humans during halothane anesthesia. Anesthesiology. 1988;68:836-42.

20. Bissonnette B, Sessler DI, LaFlamme P. Intraoperative temperature monitoring sites in infants and children and the effect of inspired gas warming on esophageal temperature. Anesth Analg. 1989;69:192-6.

21. Akata T, Kanna T, Yoshino J, Higashi M, Fukui K, Takahashi S. Reliability of fingertip skin-surface temperature and its related thermal measures as indices of peripheral perfusion in the clinical setting of the operating theatre. Anaesth Intensive Care. 2004;32:519-29.

22. Cooper KE, Kenyon JR. A comparison of temperatures measured in the rectum, oesophagus, and on the surface of the aorta during hypothermia in man. Br J Surg. 1957;44:616-9.

23. Hercus V, Cohen D, Bowring AC. Temperature gradients during hypothermia. Br Med J. 1959;1:1439-41.

24. Cohen D, Hercus V. Controlled hypothermia in infants and children. Br Med J. 1959;1:1435-9.

25. Shiraki K, Konda N, Sagawa S. Esophageal and tympanic temperature responses to core blood temperature changes during hyperthermia. J Appl Physiol. 1986;61:98-102.

26. Benzinger TH. On physical heat regulation and the sense of temperature in man. Proc Natl Acad Sci U S A. 1959;45:645-59.

27. Benzinger TH. Tympanic thermometry in surgery and anesthesia. JAMA. 1969;209:1207-11.

28. Randall WC, Rawson RO, McCook RD, Peiss CN. Central and peripheral factors in dynamic thermoregulation. J Appl Physiol. 1963; 18:61-4

29. Tanabe K, Takaori S. Effects of cooling and warming of the common carotid arteries on the brain and tympanic membrane temperatures in the rabbit. Jpn J Pharmacol. 1964;14:67-79.

30. Baker MA, Stocking RA, Meehan JP. Thermal relationship between tympanic membrane and hypothalamus in conscious cat and monkey. J Appl Physiol. 1972;32:739-42.

31. McCaffrey TV, McCook RD, Wurster RD. Effect of head skin temperature on typanic and oral temperature in man. J Appl Physiol. 1975;39:114-8.

32. Shiraki K, Sagawa F, Tajima F, Yokota A, Hashimoto M, Brengelmann GL. Independence of brain and tympanic temperatures in an unanesthetized human. J Appl Physiol. 1988;65:482-6.

33. Thomas KA, Savage MV, Brengelmann GL. Effect of facial cooling on tympanic temperature. Am J Crit Care. 1997;6:46-51.

34. Wallace CT, Marks WE, Adkins WY, Mahafey JE. Perforation of the tympanic membrane, a complication of tympanic thermometry during anesthesia. Anesthesiology. 1974;41:290-1.

\section{Appendix}

One figure (ie, Figure E1) and our Acknowledgment are provided online only. 
We thank Dr Shosuke Takahashi (Professor, Department of Anesthesiology and Critical Care Medicine, Kyushu University Hospital, Fukuoka, Japan) for his encouragement, as well as a number of anesthesia residents and staffs, and clinical engineers at the Kyushu University Hospital (Fukuoka, Japan) for their kind cooperation and helpful comments on this work. 


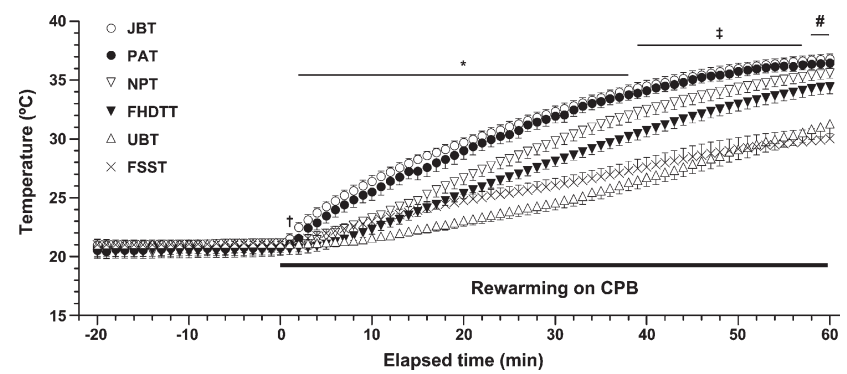

Figure E1. Changes in body temperatures during rewarming on CPB (mean \pm SEM, $\mathbf{n}=20$ ). JBT, Jugular bulb temperature; PAT, pulmonary artery temperature; NPT, nasopharyngeal temperature; FHDTT, forehead deep-tissue temperature; $U B T$, urinary bladder temperature; FSST, fingertip skin-surface temperature. The differences among 5 groups at each time point are indicated by the following symbols: ${ }^{*} P<.05:$ JBT vs NPT, FHDTT, UBT, and FSST; $† P<.05:$ JBT vs NPT, FHDTT, and UBT; $¥ P<.05:$ JBT vs FHDTT, UBT, and FSST; \# $>0.05:$ JBT vs UBT and FSST. 